Open Access

\title{
Knowledge of physical activity recommendations in adults employed in England: associations with individual and workplace-related predictors
}

\author{
Emily C. L. Knox (D, Hayley Musson and Emma J. Adams
}

\begin{abstract}
Background: Physical activity guidelines state that adults should engage in at least 150 min of moderate to vigorous physical activity (MVPA) per week to benefit health. A high proportion of adults in England fail to reach this target. Accurate knowledge of MVPA guidelines could influence the amount and quality of MVPA engaged in by adults. This study aimed to determine knowledge of the MVPA guideline within a large sample of working adults in England and identify individual and workplace-related predictors of knowledge.

Methods: 10,992 adults completed an online survey which included questions on demographics, knowledge of the MVPA guideline and workplace predictors for physical activity. Multinomial logistic regression identified predictors of underestimating, overestimating or not knowing the MVPA guideline relative to accurately reporting the guideline for males and females separately.

Results: Respondents were $37 \%$ male, $95 \%$ White, $63 \%$ with a degree or higher, and had a mean age of $38.9 \pm 11$ years. The MVPA guideline was accurately reported by $15 \%$ of adults while $13.8 \%$ overestimated, $8.9 \%$ underestimated and $62.3 \%$ failed to provide any estimate of the guideline. Low education predicted underestimation (females: $O R=0.36,95 \%$ $\mathrm{Cl} 0.17,0.80$ ) and not knowing (males: $\mathrm{OR}=0.37,95 \% \mathrm{Cl} 0.14,0.96$; females: $\mathrm{OR}=0.36,95 \% \mathrm{Cl} 0.19,0.69$ ). Ethnicity was a significant predictor for females only (OR 3.55, 95 \% Cl 1.46, 8.63; OR 4.03, $95 \% \mathrm{Cl} 1.58,10.27$; OR 3.73, $95 \% \mathrm{Cl} 1.67$, 8.33). Employer support for physical activity was a significant predictor of accurate knowledge of the MVPA guideline for both males (underestimation: $\mathrm{OR}=0.63,95 \% \mathrm{Cl} 0.40,1.00$; 'don't know': $\mathrm{OR}=0.71,95 \% \mathrm{Cl} 0.51,1.00$ ) and females (overestimation: $\mathrm{OR}=0.72,95 \% \mathrm{Cl} 0.53,0.97$; underestimation: $\mathrm{OR}=0.66,95 \% \mathrm{Cl} 0.47,0.92$; 'don't know': $\mathrm{OR}=0.60$, $95 \%$ Cl 0.47, 0.76).

Conclusions: Knowledge of the MVPA guideline within working adults in England is low. Employers should play a role in using targeted strategies to increase knowledge as employer support-related factors may influence knowledge of the MVPA guideline. Employers who assert strategies to promote physical activity and encourage employees who have responsibility for promoting health to educate their colleagues may help improve the MVPA knowledge of their employees.
\end{abstract}

Keywords: Moderate-to-vigorous physical activity, Guidelines, Workplace, Employee, Knowledge, Health

\footnotetext{
* Correspondence: e.knox@lboro.ac.uk

British Heart Foundation National Centre for Physical Activity and Health,

School of Sport, Exercise and Health Sciences, Loughborough University,

Loughborough, UK
}

\section{Biomed Central}

(c) 2015 Knox et al.; licensee BioMed Central. This is an Open Access article distributed under the terms of the Creative Commons Attribution License (http://creativecommons.org/licenses/by/4.0) which permits unrestricted use, distribution, and reproduction in any medium, provided the original work is properly credited. The Creative Commons Public Domain Dedication waiver (http://creativecommons.org/publicdomain/zero/1.0/) applies to the data made available in this article, unless otherwise stated. 


\section{Background}

Physical activity reduces the risk of morbidity and mortality from chronic diseases [1]. Physical activity guidelines state that adults should engage in at least $150 \mathrm{~min}$ a week of moderate-to-vigorous physical activity (MVPA) to obtain health benefits [2-5]. In England, only $67 \%$ of males and $55 \%$ of females meet current physical activity guidelines based on self-report measures [6]. However, objective measurements taken in 2008 using accelerometers suggest that the actual proportion of adults meeting physical activity recommendations in England is much lower at only around $6 \%$ [7].

Knowledge of physical activity guidelines has been theoretically supported as a pre-requisite to individual's positive motivation to engage in more physical activity $[8,9]$. Individuals who know how much MVPA they need to achieve to benefit their health may be more capable of judging whether or not they need to engage in more MVPA and subsequently be more likely to make positive behavioural adjustments $[10,11]$. Only one previous study has inspected knowledge of the current (i.e. as of 2011) physical activity guideline for adults. Knox et al. [12] found knowledge of the adult guideline to be $18 \%$ within a highly educated sample of 1797 adults. A better understanding of the factors associated with knowledge of guidelines will benefit attempts designed to promote and increase physical activity levels. Hunter et al. [13] identified that the factors associated with overestimating, underestimating and not being aware of guidelines differ in a sample of adults in Northern Ireland. This has important motivational implications which may impact upon decisions around the strategies which should be employed to improve knowledge.

In recent years a number of studies have been published which identify the workplace as a potentially important setting for the promotion of physical activity [14-16]. There are more than 30 million people in employment in England the majority of who spend $31 \mathrm{~h}$ or more at work each week [17]. The workplace therefore is an important setting in which adults can be reached and potentially educated with regard to recommendations for participation in physical activity to benefit health. In addition, employer support has the potential to have an impact on workers perceptions and behaviours towards physical activity. Physical aspects of the working environment such as the availability of showers, policy aspects such as the provision of programs and normative influences of co-workers can all influence physical activity $[18,19]$. Employers can also support physical activity in a number of ways such as by implementing health promotion practices [20], sponsoring public transport passes [21] and facilitating changes to workstations which encourage physical activity [22]. Knowledge of physical activity guidelines within working adults has not been previously investigated and the effect of employer promotion of physical activity and sport on knowledge of physical activity guidelines has yet to be explored.

The aim of this study was to identify the prevalence and correlates of knowledge of current physical activity recommendations within a large sample of adults working in England. Further, the hypothesis that employer support for physical activity is associated with knowledge of the MVPA guideline was explored.

\section{Methods}

Data were collected through the County Sports Partnership Network Workplace Challenge project which was part of the 'Get Healthy, Get Active' initiative funded by Sport England. 16,292 adults from workplaces across England signed up to the challenge between $1^{\text {st }}$ December 2013 and $30^{\text {th }}$ September 2014 and were invited to complete the baseline online survey. Ethical approval for the study was obtained from Loughborough University Ethical Advisory Committee (reference R13-P170).

\section{Measures \\ Dependent variable}

Participants were asked; "Do you know what the national recommendations are for taking part in physical activity, in terms of minutes per week of moderate intensity physical activity?" Participants who responded 'no' were labelled as 'don't know'. Participants who responded 'yes' were then asked "what are the national recommendations for taking part in physical activity, in terms of minutes per week of moderate intensity physical activity?" Answers of 150 min a week which is consistent with current physical activity guideline information were considered correct. Individuals giving answers of greater than 150 min a week were labelled as over-estimators and those giving answers of less than 150 min a week were labelled as underestimators.

\section{Predictor variables}

Participants were asked to provide a number of demographic variables including: age, gender, highest educational qualification, job type and employment status. Participants were asked to rate their health by responding to the statement: 'Would you say that for someone of your age your own health in general is excellent, good, fair or poor?' Participants reported the number of days each week they engaged in 30 min of physical activity using the single item measure validated by Milton et al. [23]. Next, participants were asked whether they had any responsibility for promoting health to employees working in their organisation and were also asked to select from 17 listed barriers, things which stopped them from participating in sport and physical activity (yes/no response options). The barriers were: not being active enough, time, being active not 
being a priority, not being the sporty type, poor health, having a long-term illness or disability, being overweight, being old, not being motivated, not being bothered, having no-one to do it with, cost, lack of facilities, lack of clubs or classes, having young children, fear of injury or ill health and other [24]. Finally, participants were asked to rate on a four-point scale from strongly agree to strongly disagree four statements relating to their employers support and provision for health and physical activity/sport. All statements began with the stem 'My employer...' and read: 'promotes health and well-being' and 'promotes participation in sport and physical activity'. Response categories strongly agree and agree were later combined, as were disagree and strongly disagree to provide bivariate employer support variables for analysis.

\section{Statistical analysis}

Descriptive statistics were calculated using frequencies for categorical variables and mean $\pm 95 \%$ confidence intervals (CI) for continuous variables. IBM SPSS Statistics 22 was used with alpha set at 0.05 . Multinomial regression models were developed including demographic variables alongside variables which were hypothesised to influence knowledge of physical activity guidelines based on previous research. The nominal indicator of 'accurate knowledge' was assigned as the reference category. Evidence suggests that predictors of knowledge of physical activity guidelines differ between men and women [13] and so separate analyses were conducted for males and females. Variables found not to contribute to the prediction of the dependent variable were excluded from the final model.

\section{Ethics, consent and permissions}

All participants provided informed consent before taking part in this research.

\section{Results}

A total of 10992 adults provided data on knowledge of the MVPA guideline and were included in the analysis. Individual and demographic characteristics are provided in Table 1 . The sample was $37 \%$ male, $95 \%$ white and had a mean age of $38.9 \pm 11$ years. Over half $(63 \%)$ had a degree or higher and $81 \%$ were in good or excellent health. A high proportion of respondents did not participate in sufficient physical activity to meet the recommended guideline (70.1\%). The proportion of respondents reporting barriers to participation in sport and physical activity is presented in Table 2 and perceived employer support for sport and physical activity in Table 3.

The physical activity guideline was accurately reported by $15 \%$ of adults while $13.8 \%$ overestimated, $8.9 \%$ underestimated and $62.3 \%$ reported they did not know the guidelines (Table 4). No gender differences were found.
Table 1 Individual characteristics $(n=10,992)$, $n$ and $\%$ unless otherwise stated

\begin{tabular}{|c|c|c|}
\hline Characteristic & Number & Percent \\
\hline \multicolumn{3}{|l|}{ Gender } \\
\hline Male & 4,120 & 37.5 \\
\hline Female & 6,872 & 62.5 \\
\hline \multicolumn{3}{|l|}{ Age, years } \\
\hline Mean $\pm 95 \% \mathrm{Cl}$ & 38.90 & $\begin{array}{l}38.69 \\
39.10\end{array}$ \\
\hline \multicolumn{3}{|l|}{ Ethnic group } \\
\hline Mixed & 142 & 1.3 \\
\hline Black/Black British & 177 & 1.6 \\
\hline Asian/Asian British & 197 & 1.8 \\
\hline White British & 10,357 & 95.3 \\
\hline \multicolumn{3}{|l|}{ Highest educational qualification } \\
\hline Degree & 6,967 & 63.4 \\
\hline $\begin{array}{l}\text { Business and Technology Education Council (BTEC) } \\
\text { Higher/Advanced Level (A Level) }\end{array}$ & 2,332 & 21.2 \\
\hline $\begin{array}{l}\text { BTEC National/General Certificate of Secondary } \\
\text { Education (GCSE) }\end{array}$ & 1,422 & 12.9 \\
\hline None/other & 271 & 2.5 \\
\hline \multicolumn{3}{|l|}{ Job type } \\
\hline Managerial e.g. office manager, finance manager & 3,081 & 29.5 \\
\hline Professional e.g. nurse, teacher, police officer & 4,127 & 39.5 \\
\hline Clerical/Admin e.g. secretary, office worker & 2,799 & 26.8 \\
\hline Manual/Technical e.g. postal worker, farm worker & 443 & 4.2 \\
\hline \multicolumn{3}{|l|}{ General health } \\
\hline Excellent/Good & 8,894 & 80.9 \\
\hline Fair/Poor & 2,096 & 19.1 \\
\hline \multicolumn{3}{|l|}{ Physical activity engagement } \\
\hline Meets guidelines ( $\geq 150$ mins/week) & 3,284 & 29.9 \\
\hline Doesn't meet guidelines (<150 mins/week) & 7,708 & 70.1 \\
\hline
\end{tabular}

Tables 5 and 6 present the odds ratios (OR), $95 \%$ confidence intervals $(\mathrm{CI})$ and p-values for knowledge of physical activity recommendations for males and females respectively. Analysis for the total sample is also provided in Additional file 1. Overestimation of the physical activity guideline within males was predicted by increasing age, not meeting recommendations for moderate-to-vigorous physical activity and not having personal responsibility to promote health at work. Overestimation within females was predicted by being of Black or Asian ethnicity, selfreporting poor health, reporting not being 'sporty' as a barrier to physical activity, having an employer who is perceived not to support physical activity and/or sport, not having personal responsibility to promote health at work and not meeting physical activity recommendations.

Underestimation of the physical activity guideline within males was predicted by reporting not being 'sporty' as a 
Table 2 Physical activity barriers $(n=10,992)$

\begin{tabular}{lrr}
\hline What are the main things that stop you from & Number & Percent \\
participating in sport and physical activity? & & \\
\hline I'm not active enough & 801 & 7.3 \\
Yes & 10,191 & 92.7 \\
No & & \\
Time & 4,507 & 41 \\
Yes & 6,485 & 59 \\
No & & \\
Being active is not a priority for me & 139 & 1.3 \\
Yes & 10,853 & 98.7 \\
No & &
\end{tabular}

I'm not the sporty type

Yes

No

My health is not good enough $(n=10,395)$

Yes

No

I have a long-term illness or disability

Yes

No

I'm too overweight

Yes

No

I'm too old

Yes

No

I'm not motivated

Yes

No

I can't be bothered

Yes

No

There is no-one to do it with

Yes

No

Cost

Yes

No

There are no suitable facilities

Yes

No

There are no suitable clubs or classes

Yes

No

I've got young children to look after
Table 2 Physical activity barriers $(n=10,992)$ (Continued)

\begin{tabular}{lrr}
\hline Yes & 1,438 & 13.1 \\
No & 9,554 & 86.9 \\
I might get injured or damage my health & \\
Yes & 259 & 2.4 \\
No & 10,733 & 97.6 \\
Other* & & \\
Yes & 617 & 5.6 \\
No & 10,375 & 94.4 \\
\hline${ }^{*}$ most commonly reported other barrier was having a current injury &
\end{tabular}

barrier to physical activity, having an employer who is perceived not to support physical activity and/or sport and not having personal responsibility to promote health at work. Underestimation within females was predicted by being of Asian ethnicity, low educational attainment, having an employer who is perceived not to support physical activity and/or sport and not having personal responsibility to promote health at work.

Reporting "don't know" within males was predicted by increasing age, low educational attainment, having a technical/manual job instead of a managerial or professional job (nurse, teacher, police officer etc.), self-reporting poor health, reporting not being 'sporty' as a barrier to physical activity, having an employer who is perceived not to support physical activity and/or sport, not having personal responsibility to promote health at work and not meeting recommendations for moderate-to-vigorous physical activity. Reporting "don't know" within females was predicted by increasing age, Asian ethnicity, low educational attainment, poor health, reporting not being 'sporty' as a barrier to physical activity, having an employer who is perceived not to support physical activity and/or sport, not having personal responsibility to promote health at work and not meeting physical activity recommendations.

Table 3 Workplace-related predictors $(n=10,992)$

\begin{tabular}{lcc}
\hline & Number & Percent \\
\hline $\begin{array}{l}\text { I am responsible for promoting health at work } \\
(n=10,985)\end{array}$ & & \\
Yes & 1,976 & 18.0 \\
No & 9,009 & 82.0 \\
My employer promotes health and wellbeing & & \\
$(\mathrm{n}=10900)$ & & \\
Yes & 8,953 & 82.1 \\
No & 1,947 & 17.9 \\
My employer promotes participation in sport & & \\
and physical activity ( $n=10,850)$ & & \\
Yes & 7,669 & 70.7 \\
No & 3,181 & 29.3 \\
\hline
\end{tabular}


Table 4 Knowledge of physical activity guidelines, overall and by gender

\begin{tabular}{lllllll}
\hline Knowledge & Overall & \multicolumn{2}{c}{ Males } & \multicolumn{3}{c}{ Females } \\
& \multicolumn{1}{c}{$\mathrm{n}$} & \multicolumn{1}{c}{$\%$} & \multicolumn{1}{c}{$\mathrm{n}$} & \multicolumn{1}{c}{$\%$} & \multicolumn{1}{c}{$\mathrm{n}$} & \multicolumn{1}{c}{$\%$} \\
\hline Correct & 1,642 & 15.0 & 572 & 14.0 & 1,070 & 15.7 \\
Overestimate & 1,504 & 13.8 & 524 & 12.8 & 980 & 14.3 \\
Underestimate & 970 & 8.9 & 340 & 8.3 & 630 & 9.2 \\
Don't know (no guess) & 6,805 & 62.3 & 2654 & 64.9 & 4,151 & 60.8 \\
\hline
\end{tabular}

\section{Discussion}

Results indicated a low prevalence of knowledge of the MVPA guideline (15\%) within this sample of adults employed in England. Similar results have been reported within another sample of UK adults [12]. Both the Knox et al. sample and the present sample were highly educated relative to the population [12]. This research therefore, highlights the need for educational intervention even amongst highly educated and employed adults.

Table 5 Multinomial logistic regression model - predictors of knowledge of physical activity guidelines - male sample $(n=4,120)$

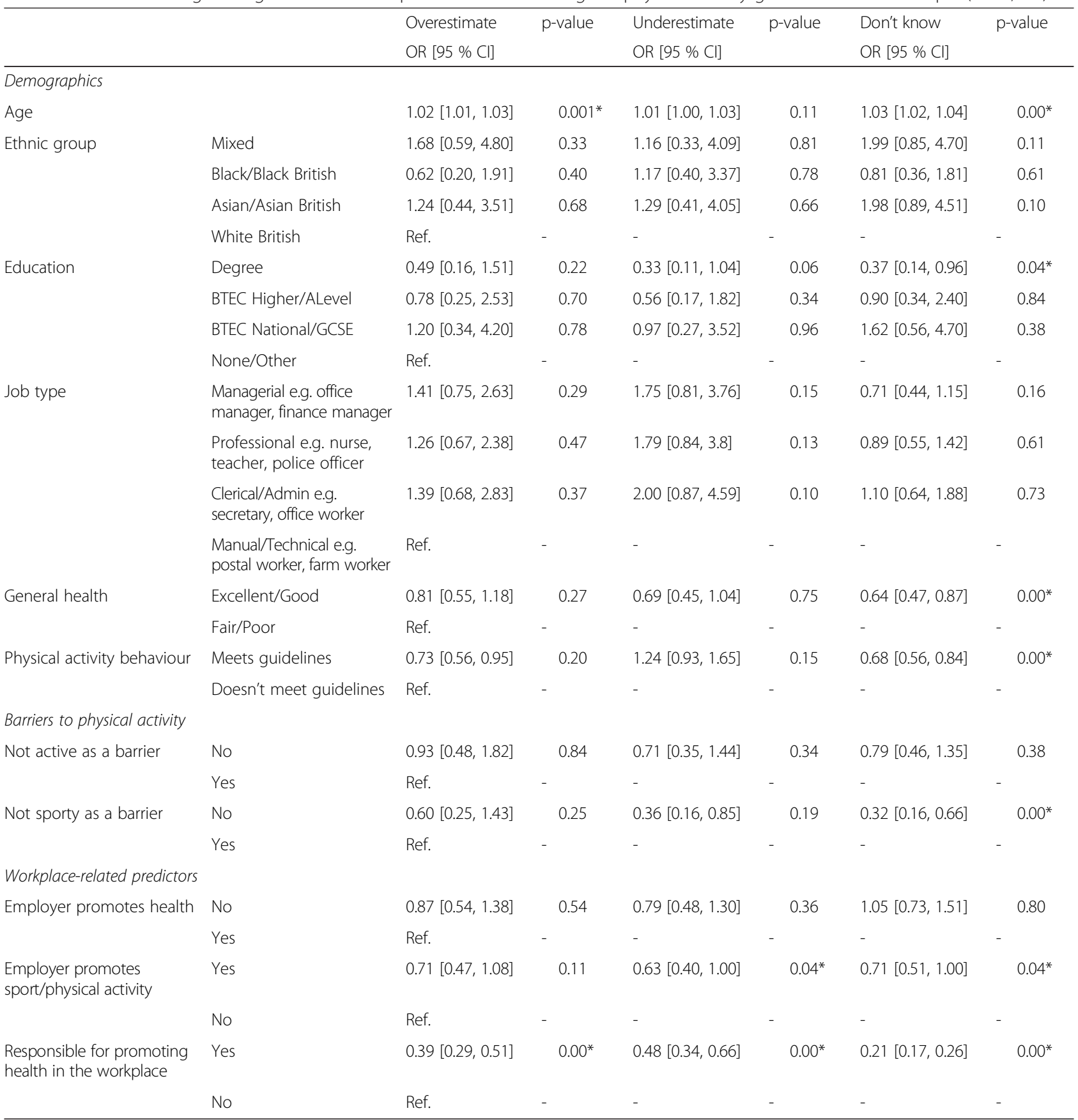




\begin{tabular}{|c|c|c|c|c|c|c|c|}
\hline & & Overestimate & $p$-value & Underestimate & $p$-value & Don't know & $p$-value \\
\hline & & \multicolumn{2}{|l|}{ OR $[95 \%$ Cl] } & \multicolumn{2}{|l|}{ OR $[95 \% \mathrm{Cl}]$} & \multicolumn{2}{|l|}{ OR $[95 \% \mathrm{Cl}]$} \\
\hline \multicolumn{8}{|l|}{ Demographics } \\
\hline Age & & $1.01[1.00,1.02]$ & 0.21 & $1.00[0.99,1.01]$ & 0.98 & $1.01[1.00,1.02]$ & $0.04^{*}$ \\
\hline \multirow[t]{4}{*}{ Ethnic group } & Mixed & $0.76[0.34,1.73]$ & 0.52 & $0.46[0.15,1.42]$ & 0.18 & $0.71[0.37,1.34]$ & 0.29 \\
\hline & Black/Black British & $2.67[1.26,5.67]$ & $0.01^{*}$ & $1.78[0.74,4.39]$ & 0.20 & $1.92[0.96,3.82]$ & 0.06 \\
\hline & Asian/Asian British & $3.55[1.46,8.63]$ & $0.01^{*}$ & $4.03[1.58,10.27]$ & $0.00^{*}$ & $3.73[1.67,8.33]$ & $0.00^{*}$ \\
\hline & White British & Ref. & - & - & - & - & - \\
\hline \multirow[t]{4}{*}{ Education } & Degree & $0.71[0.32,1.58]$ & 0.40 & $0.36[0.17,0.80]$ & $0.01^{*}$ & $0.36[0.19,0.69]$ & $0.00^{*}$ \\
\hline & BTEC Higher/ALevel & $0.99[0.43,2.27]$ & 0.98 & $0.52[0.23,1.16]$ & 0.11 & $0.66[0.34,1.29]$ & 0.23 \\
\hline & BTEC National/GCSE & $1.35[0.57,3.17]$ & 0.50 & $0.78[0.34,1.83]$ & 0.57 & $1.03[0.52,2.05]$ & 0.94 \\
\hline & None/Other & Ref. & - & - & - & - & - \\
\hline \multirow[t]{4}{*}{ Job type } & $\begin{array}{l}\text { Managerial e.g. office } \\
\text { manager, finance } \\
\text { manager }\end{array}$ & $0.72[0.37,1.41]$ & 0.34 & $0.64[0.31,1.35]$ & 0.24 & $0.49[0.28,0.85]$ & 0.12 \\
\hline & $\begin{array}{l}\text { Professional e.g. nurse, } \\
\text { teacher, police officer }\end{array}$ & $0.65[0.33,1.26]$ & 0.20 & $0.70[0.34,1.44]$ & 0.33 & $0.47[0.27,0.82]$ & $0.01^{*}$ \\
\hline & $\begin{array}{l}\text { Clerical/Admin e.g. } \\
\text { secretary, office worker }\end{array}$ & $0.86[0.44,1.68]$ & 0.66 & $0.79[0.38,1.64]$ & 0.53 & $0.76[0.44,1.33]$ & 0.34 \\
\hline & $\begin{array}{l}\text { Manual/Technical e.g. } \\
\text { postal worker, farm } \\
\text { worker }\end{array}$ & Ref. & - & - & - & - & - \\
\hline \multirow[t]{2}{*}{ General health } & Excellent/Good & $0.70[0.53,0.91]$ & $0.01^{*}$ & $0.74[0.55,1.00]$ & 0.05 & $0.57[0.46,0.71]$ & $0.00^{*}$ \\
\hline & Fair/Poor & Ref. & - & - & - & - & - \\
\hline \multirow[t]{2}{*}{ Physical activity behaviour } & Meets guidelines & $0.70[0.57,0.85]$ & $0.00^{*}$ & $1.04[0.83,1.30]$ & 0.76 & $0.65[0.56,0.77]$ & $0.00^{*}$ \\
\hline & Doesn't meet guidelines & Ref. & - & - & - & - & - \\
\hline \multicolumn{8}{|l|}{ Barriers to physical activity } \\
\hline \multirow[t]{2}{*}{ Not active as a barrier } & No & $0.88[0.60,1.30]$ & 0.53 & $0.86[0.55,1.34]$ & 0.49 & $0.77[0.55,1.06]$ & 0.11 \\
\hline & Yes & Ref. & - & - & - & - & - \\
\hline \multirow[t]{2}{*}{ Not sporty as a barrier } & No & $0.70[0.51,0.98]$ & $0.04^{*}$ & $0.85[0.58,1.34]$ & 0.40 & $0.75[0.57,0.99]$ & $0.04^{*}$ \\
\hline & Yes & Ref. & - & - & - & - & \\
\hline \multicolumn{8}{|l|}{$\begin{array}{l}\text { Workplace-related } \\
\text { predictors }\end{array}$} \\
\hline \multirow[t]{2}{*}{ Employer promotes health } & No & $0.94[0.68,1.30]$ & 0.70 & $0.78[0.54,1.12]$ & 0.18 & $0.85[0.66,1.11]$ & 0.24 \\
\hline & Yes & Ref. & - & - & - & - & - \\
\hline \multirow{2}{*}{$\begin{array}{l}\text { Employer promotes sport/ } \\
\text { physical activity }\end{array}$} & Yes & $0.72[0.53,0.97]$ & $0.03^{*}$ & $0.66[0.47,0.92]$ & $0.02^{*}$ & $0.60[0.47,0.76]$ & $0.00^{*}$ \\
\hline & No & Ref. & - & - & - & - & - \\
\hline \multirow{2}{*}{$\begin{array}{l}\text { Responsible for promoting } \\
\text { health in the workplace }\end{array}$} & Yes & $0.5[0.40,0.62]$ & $0.00^{*}$ & $0.52[0.41,0.66]$ & $0.00^{*}$ & $0.29[0.24,0.34]$ & $0.00^{*}$ \\
\hline & No & Ref. & - & - & - & - & - \\
\hline
\end{tabular}

Reference category: Correctly reports physical activity guidelines. * statistically significant $(p<0.05)$

Similarly to Hunter et al. [13], the present study found distinct predictors of overestimation, underestimation and being unaware of physical activity recommendations. For instance, low education predicted overestimation and not knowing guidelines. Thus, less educated individuals may perceive an adequate amount of physical activity to be unattainable which could result in demotivation. We also found ethnicity to only predict overestimation, underestimation and not knowing the guideline within females. This suggests that certain female communities may require targeted promotions. Further examination of these factors is required.

The present study presents the first findings regarding the influence of employer support-related factors on knowledge 
of physical activity guidelines which is a determinant of physical activity behaviour $[8,9]$. Lucove et al. [16] previously found that adults who perceived their workplace to have physical activity policies such as, on-site facility access and subsidies for health-clubs, were more likely to be engaging in physical activity than those who did not perceive their workplace to have such policies. The present findings suggest that employers could have a powerful influence on employee's knowledge of physical activity guidelines. Lack of employer support for physical activity emerged as a predictor of overestimating, underestimating and not knowing the guideline, especially for females. More comprehensive investigation of these findings, including additional employer and workplace-related predictors in recognition of the likely complexity of this relationship is warranted. Employers could, however, play a role in educating their employees as to the current recommendations for participating in physical activity, as well as employing strategies such as role-modelling physical activity behaviour (i.e. being active themselves), rewarding active travel, initiating schemes to incentivise physical activity (e.g. collecting activity points which can be redeemed for prizes), sponsoring active breaks or encouraging walking meetings, providing an environment which supports physical activity e.g. installing lockers, bike sheds and showers etc., informing employees about active opportunities in the local area and advocating physical activity in regular workplace newsletters or bulletins. In addition, employees who highlighted themselves as being responsible for promoting health in the workplace were more likely to know the guideline. Thus, employers could utilise these members of staff to assist with educating other employees.

A further finding of the present research was that adults who reported 'not being "sporty" enough' as a barrier to engaging in physical activity were less likely to accurately report the physical activity guideline. On the other hand, reporting 'not being active' as a barrier to engaging in physical activity did not predict a lack of knowledge. The physical activity guidelines were designed to summarise evidence on the level of activity required to achieve health benefits. They may not be sufficiently accessible for individuals of all activity levels and may be failing to inspire the least active to engage in physical activity by encouraging generally active lifestyles, which does not have to be achieved through sport [2]. It is possible that some individuals are unable to differentiate between physical activity and sport and this could also be impeding accurate health knowledge. This highlights the need for public facing messages to be developed to aid communication of the physical activity guidelines and increase understanding of the levels of participation required, as well as the steps that can be taken to achieve these levels. It may be beneficial for workplaces to promote physical activity guidelines, within general wider promotional efforts towards a more active lifestyle. For instance, workplaces could encourage taking ten minute walk breaks at lunch as a way of accumulating the recommended $150 \mathrm{~min}$ a week of MVPA.

The findings reported in the present study are crosssectional in nature and so cannot be used to infer causality requiring cautious interpretation. There are also a number of limitations to online survey research such as lack of control over the test environment and inability to measure sampling frame. Further, some of the measures employed have not been reliability tested and our sample was both highly educated, more likely to be employed and less representative of ethnic minorities relative to the general population. Finally, as data was collected through the County Sports Partnership Network Workplace Challenge there may have also been a degree of selection bias, though it must be noted that knowledge of the MVPA guideline was still low. As the first study to assess knowledge of guidelines in a large sample of adults working in England and to specifically consider employer supportrelated influences we believe the results can still provide useful insights into this targeted population.

\section{Conclusions}

The present study identified a low prevalence of knowledge of the MVPA guideline within employed adults in England. Employers have a potential role to play in educating employees in relation to the current physical activity guidelines and those who actively promote and support involvement in physical activity can contribute significantly to better health knowledge and so should be targeted as important sources of social influence.

\section{Additional file}

Additional file 1: Table A1. Multinomial logistic regression model predictors of knowledge of physical activity guidelines - total sample ( $N=10992)$.

\section{Competing interests}

The authors declare that they have no competing interests.

\section{Authors' contributions}

EA is the Principal Investigator for the evaluation of the County Sports Partnership Network Workplace Challenge project, conceived the idea for the paper and designed the baseline survey. EA and HM collected the baseline data. EK analysed and interpreted the data, wrote the first draft of the paper and critically reviewed and revised the manuscript. EA and HM critically reviewed and revised versions of the manuscript. All authors read and approved the final manuscript.

\section{Acknowledgements}

EA was commissioned by the County Sports Partnership Network to undertake an independent evaluation of the Workplace Challenge project. The authors would like to thank Sport England for funding this project through the Lottery supported 'Get Healthy, Get Active' portfolio. This activity was conducted under the auspices of the National Centre for Sport and Exercise Medicine (NCSEM) England, a collaboration between several universities, NHS trusts and sporting and public bodies. The views expressed are those of the authors and not necessarily those of NCSEM England or the partners involved. We thank the study participants for taking part in this project. 
Received: 18 February 2015 Accepted: 15 May 2015

Published online: 23 May 2015

\section{References}

1. Lee IM, Shiroma EJ, Lobelo F, Puska P, Blair SN, Katzmarzyk PT. Effect of physical inactivity on major non-communicable diseases worldwide: an analysis of burden of disease and life expectancy. Lancet. 2012;380:219-29.

2. Department of Health Physical Activity Health Improvement and Protection. Start active, stay active: a report on physical activity for health from the four home Countries' chief medical officers. London: Department of Health; 2011.

3. US Department of Health and Human Services. 2008 physical activity guidelines for Americans. Washington, DC: Centers for Disease Control; 2008.

4. Tremblay MS, Warburton DER, Janssen I, Paterson DH, Latimer AE, Rhodes RE, et al. New Canadian physical activity guidelines. Appl Physiol Nutr Metab. 2011;36:36-58.

5. World Health Organization. Global recommendations on physical activity for health. Geneva, Switzerland: WHO Press; 2010.

6. The Health and Social Care Information Centre. Health Survey for England 2012 Volume 1: Health, Social Care and Lifestyles. (Craig R, Mindell J, eds.). London: The Health and Social Care Information Centre; 2013.

7. Chaudhury M, Esliger D. Accelerometry in adults. In: Craig R, Mindell J, Hirani V, editors. Health survey for England 2008: volume 1 physical activity and fitness, vol. 1. Leeds: The Health and Social Care Information Centre; 2009.

8. Weinstein ND. The precaution adoption process. Heal. Psychol. 1988;7(4):355-386. Available at: http://psycnet.apa.org/journals/hea/7/4/355/.

9. World Health Organization. Health Education: Theoretical Concepts, Effective Strategies and Core Competencies. Cairo, Eastern Mediterranean Region: World Health Organization; 2012:1-82. doi:10.1177/1524839914538045.

10. Van Sluijs EMF, Griffin SJ, van Poppel MNM. A cross-sectional study of awareness of physical activity: associations with personal, behavioral and psychosocial factors. Int J Behav Nutr Phys Act. 2007:4:53-61.

11. Watkinson C, van Sluijs EMF, Sutton S, Hardeman W, Corder K, Griffin SJ. Overestimation of physical activity level is associated with lower BMl: a cross-sectional analysis. Int J Behav Nutr Phys. 2010;7:68-76.

12. Knox ECL, Esliger DW, Biddle SJH, Sherar LB. Lack of knowledge of physical activity guidelines: Can physical activity promotion campaigns do better? BMJ Open. 2013;3:1-6.

13. Hunter RF, Tully MA, Donnelly P, Stevenson M, Kee F. Knowledge of UK physical activity guidelines: Implications for better targeted health promotion. Prev Med. 2014;65:33-9.

14. Barr-Anderson DJ, AuYoung M, Whitt-Glover MC, Glenn BA, Yancey AK. Integration of short bouts of physical activity into organizational routine a systematic review of the literature. Am J Prev Med. 2011;40:76-93.

15. Abraham C, Graham-Rowe E. Are worksite interventions effective in increasing physical activity? a systematic review and meta-analysis. Health Psychol Rev. 2009;3:108-44.

16. Lucove JC, Huston SL, Evenson KR. Workers' perceptions about worksite policies and environments and their association with leisure-time physical activity. Am J Heal Promot. 2007;21:196-200.

17. Office for National Statistics. A01: Summary of labour market statistics. Date of publication: 21 January 2015. Date of next publication: 18 February 2015. Data tables. Available at: http://www.ons.gov.uk/ons/taxonomy/ index.html?nscl = Average + Hours\#tab-data-tables. Accessed January 27, 2015

18. Crespo NC, Sallis JF, Conway TL, Saelens BE, Frank LD. Worksite physical activity policies and environments in relation to employee physical activity. Am J Heal Promot. 2011;25:264-71.

19. Campbell M, Bopp M. An examination of the relationship of interpersonal influences with walking and biking to work. J Public Heal Manag Pract. 2013;19:521-4.

20. Laing SS, Hannon PA, Talburt A, Kimpe S, Harris JR. Increasing evidence-based workplace health promotion best practices in small and low-wage companies, Mason County, Washington, 2009. Prev Chronic Dis. 2012;9:1-9.

21. Lachapelle U, Frank LD. Transit and health: Mode of transport, employersponsored public transit pass programs, and physical activity. J Public Heal Policy. 2009;30 Suppl 1:S73-94.
22. Tudor-Locke C, Schuna JM, Frensham LJ, Proenca M. Changing the way we work: Elevating energy expenditure with workstation alternatives. Int J Obes. 2014;38:755-76.

23. Milton K, Bull FC, Bauman A. Reliability and validity testing of a single-item physical activity measure. Br J Sports Med. 2011;45:203-8.

24. The NHS Information Centre. Health Survey for England 2007: Volume 2. Methodology and Documentation. (Craig R, Shelton N, eds.). Leeds: The Health and Social Care Information Centre; 2008.

\section{Submit your next manuscript to BioMed Central and take full advantage of:}

- Convenient online submission

- Thorough peer review

- No space constraints or color figure charges

- Immediate publication on acceptance

- Inclusion in PubMed, CAS, Scopus and Google Scholar

- Research which is freely available for redistribution

Submit your manuscript at www.biomedcentral.com/submit 